\title{
Communication Overload: A Phenomenological Inquiry into Academic Reference Librarianship
}

\author{
C. Sean Burns, School of Information Science \& Learning Technologies, University of \\ Missouri, Columbia, Missouri, USA \\ Jenny Bossaller, School of Information Science \& Learning Technologies, University of \\ Missouri, Columbia, Missouri, USA
}

The impetus for this study was personal experience: that of being overwhelmed by communication coming from multiple venues, and repeated attempts to find 'the magic bullet' to gather, or filter, communication in order to make it manageable. Personal adaptation of technology is often by choice; the choices can be confusing, but they are a choice. Reference librarians' jobs depend on effective communication with different types of library users, and increasingly using mediated technology. Furthermore, the technology that they use is not always their choice. Finding the magic bullet might prove more elusive as those users vary, and are fickle regarding allegiance to technology. That situation prompted the research question: how do librarians experience the varied landscape of communication tools today? Do they feel that they are able to control their communication environment and work well within it, or are they overwhelmed?

The purpose of this study is threefold: to provide insight into how a communication rich environment is experienced as communication overload; to identify significant themes embedded within the lived experience of everyday reference librarianship within this environment; and to understand the essence of reference librarianship as it exists within a communication rich environment.

Communication studies in library and information science often examine the particular interactions between librarians and their users (e.g., Dervin, 1977; Radford 1996; Radford, 2001). This study inquires into the librarians' general communication practices and environment. It specifically asks: are academic reference librarians overwhelmed with communicative tools, methods, and with communication in general? The phenomenon or experience of feeling overwhelmed by communication technologies has been referred to as communication overload. It is the particular subjective experience felt as a response to excessive communication through multiple channels using various information and communication technologies (ICTs). As studies have noted, academic librarians' jobs have changed in response to ICTs (Janes, 2002). Due to these changes, we seek to understand if academic reference librarians are experiencing communication overload, and if so, how they make sense of it. This study draws from in-depth interviews with nine reference librarians at five university libraries. 
The phenomenological research design yields a rich understanding of the library as workplace and of librarianship as profession.

This paper starts with a discussion of pertinence---why communication overload is a general concern for both society and librarians. The second part discusses the phenomenological research design and outlines the method used in this study. The third part reveals our findings and this includes the themes that emerged from the analysis of interview transcripts. The next section articulates the overall essence, the shared meaning, of 21st century librarianship, and discusses the manifestation of communication overload expressed by the participants. We conclude with some comments on the limitations and implications of this project and offer suggestions for further research.

\section{Background and Literature Review}

Librarians work with many information and communication technologies to provide service to their users and to reach and market those in their community. Dempsey (2009) furnishes an array of the "entry points" currently available:

We increasingly have a 'mesh' of entry points: PC and phone, of course, but also DVRs, cameras, navigation systems, and consoles. We increasingly use a range of shared network level 'cloud' services: for search, for social networking, for content and information, for communication ("The diffusion of networking," para. 4).

This array may be more pronounced when we consider the uses of these entry points. Before the Web revolution, librarians mastered a comparably minute number of communication channels that involved information skills with print and other hard copy resources. Librarians met with users in face to face settings, spoke with them on telephones, and provided answers through the post. Today's reference landscape is dominated by search engine sites, social media applications, online resources, and the devices used to access these services, and it still requires knowledge of traditional print sources (Wu, 2005). To keep pace with technological advancements with both devices and applications, librarians must be proficient with multiple technologies (or at least they must feel as if they are; see Melchionda, 2007) to communicate and inform their users about their own and their libraries' capabilities. 
The pressure noted above has been discussed as a problem with the general population also. Savolainen (1995) found that too much communication results in excessive distractions with cognitive and affective consequences. In the popular literature, numerous newspaper articles, magazine articles, and blog posts have reported or commented on the negative aspects of our modern communication environment, signifying a growing societal concern with various types of overload (i.e., digital, information, media, technological). For example, consider the concerns reflected in the following titles:

- Carr (2008), "Is Google Making Us Stupid?", The Atlantic

- Lamb (2010), "Are iPads, Smartphones, and the Mobile Web Rewiring the Way We Think?", The Christian Science Monitor

- Richtel (2010a), interview with Terry Gross and Matt Richtel, "Digital Overload: Your Brain on Gadgets", Fresh Air from WHYY, NPR

- Connelly (2010), "More Americans Sense a Downside to an Always Plugged-In Existence" The New York Times

- Richtel (2010b), "Digital Devices Deprive Brain of Needed Downtime", The New York Times

This list is a very small selection of articles describing a virtual assault on concentration.

Academic studies and corporate reports mirror these concerns. Dawley and Anthony (2003) write that the abundance of communication, usually in the form of email, causes an information overload defined as "the glut of e-mail that an employee must sift through in an attempt to reduce superfluous information to a manageable level" (p. 170). In 1997, Sibley comments on a Pitney Bowes, Inc. report citing one of the "biggest irritants in modern life" was "information overload in the form of voice mail, e-mail, fax messages, software shareware, cell phone, pagers, message slips, snail mail, courier packages and interdepartmental mail...[resulting in] little time for actually doing any work" (p. 6). This increased number of communication channels and volume in messages sent and received resulted in overwhelming stress in workers. The term used to describe this phenomenon was communication overload.

The above quotes refer to an often-discussed concept called information overload. Case (2007) summarizes information overload "as the number of alternatives that need to be examined, multiplied by the number of their attributes, which are the 
ways that things can differ from one another" (pp. 87-88). Bawden and Robinson (2008) write that "the idea that there is too much information to hand, exacerbated by the multiple formats and channels available for its communication, has led to the concept of information overload" (p. 182). Associated with this concept are terms such as "infobesity, information avoidance, information anxiety and library anxiety" (p. 182). They find that,

there is no single generally accepted definition of information overload. The term is usually taken to represent a state of affairs where an individual's efficiency in using information in their work is hampered by the amount of relevant, and potentially useful, information available to them. The information must be of some potential value, or it could be ignored, and it must be accessible, or the overload will only be potential, not actual (pp. 182-183).

Resolving the conceptual confusion about information overload might begin with distinguishing it from communication overload. We receive information through communication. That is, we might say that communication is a necessary (but perhaps insufficient) condition for receiving or transmitting information; therefore, studying the problems associated with communication channels and sources may inform the higher order problems associated with informational content and its cognitive effects. However, the two concepts share the problem of excess and the potential for overload as an outcome of this excess. Therefore, we do not reject the possibility of being informed by information overload studies. However, since information overload studies more often describe the cognitive effects of information, or something like it, rather than information itself, they are more about overload than about information. Thus, as a shared concept, overload becomes the defining factor. For example, in Savolainen's (2007) case study of environmental activists, he identifies two strategies for managing information overload: the filtering strategy and the withdrawal strategy. Based on the above analysis, we argue that the filtering strategy pertains to the cognitive element and is a strategy used to identify, retain, and discard information based on, perhaps, its relevance and pertinence to the person. The withdrawal strategy focuses on information sources, or we might suppose, the communication channels. Savolainen describes the withdrawal strategy as an attempt at "minimizing the number of information sources used daily. Those favouring this approach attempted to protect themselves from excessive information bombardment in order to retain peace of mind" (p. 618).

Interruption science offers another explanation of the problem under scrutiny in this study. Mark et.al. (2008) conducted an experiment to discover if the way a worker receives interruptions makes a difference in their work performance. They found that the type of interruption (IM or telephone) did not make a difference, but that the worker's 
personality did. Interrupted tasks were completed as quickly as uninterrupted tasks because the workers compensated for lost time, but they were less thorough, and came with a cost: "After only 20 minutes of interrupted performance people reported significantly higher stress, frustration, workload, effort, and pressure" (p. 110).

Other terms describe the complexities with communication and information. KarrWisniewski and Lu (2010) use the broad term technology overload under which communication overload, along with related concepts system feature overload and information overload, operate as "human factor dimensions" (p. 1064). They tie such concepts to "the controversy about the 'Productivity Paradox'" (p. 1061), which describes the relationship between modern advances and abundances in technology with a decline in productivity. Technology overload emphasizes our dependence on all information and communication technologies. Karr-Wisniewski and Lu argue that "technology itself has become an 'organizational actor,' not just a resource, for whom knowledge workers rely to achieve goals, perform tasks, and ultimately transform work patterns" (p. 1062).

In this study, we use Karr-Wisniewski and Lu's (2010) framework for conceptualizing the distinctions among these concepts: "communication overload occurs when a third party solicits the attention of the knowledge worker through such means as email, instant messaging, or mobile devices that cause excessive interruptions in his or her job to the point the knowledge worker becomes less productive" (p. 1063). Hence, these interrupting events become a focal point and part of the object of study. Interruptions suggests that communication overload is not merely tied to an abundance of communication channels but also to the constant passive and active (e.g., monitoring, receiving, and sending) use of these channels. They find that communication overload, when framed in this way, is a substantial worry. Eighty-six percent of their survey respondents identify communication overload as the most problematic when compared to system feature overload (55\%) and information overload (47\%) (p. 1064).

\section{The Phenomenological Approach}

Returning to the research questions (How do librarians experience the varied landscape of communication tools today? Do they feel that they are able to control their communication environment and work well within it, or are they overwhelmed?) the phenomenological method seems especially appropriate. Budd (2005) discusses the appropriateness of the phenomenological approach in LIS; specifically, he discusses its utility in analyzing information needs. The phenomenological research design provides an understanding of a thing that one experiences; in order to confirm its existence, the researcher looks to descriptions provided by other people of that particular thing. While 
two people will rarely express ideas using the same words, universal concepts (truths) emerge from the data as evidence of shared experience (Bernet et al., 1993). In other words, it "transforms information to knowledge" (Budd, 2005, p. 47). This has been described as the process of meaning making, which "takes place at the intersection of the physical world in which experience transpires and the mental and emotional world of the participant. This person-world intersect is where phenomenology seems to best lend itself to discovery" (Conklin, 2007, p. 277).

The phenomenological method requires the researcher to possess a knowledge of the subject, but it also demands him to lay aside personal preconceptions during the coding process, a process known as bracketing or epoche, described by Conklin (2007) as the process by which "a researcher attempts to put in abeyance presuppositions and prejudices she may carry with her into the field" (p. 277). Chamberlin (1974) thus described the phenomenological method as a means of achieving objectivity:

To discern the meaning of an object (idea, process, person, house) one does not respond to one's perceptions of that object from one perspective only. Such a view may be a profile, but the consciousness is aware that a house can be viewed from many other perspectives, and that all the different perceptions are still of the same object (p. 129).

\section{Procedure}

The researchers gathered data from nine semi-structured interviews with academic reference librarians at both mid-size and research universities. This study received exempt approval from The University of Missouri Institutional Review Board (IRB \#1180038). All participants agreed to interviews following an explanation of the purpose of the research and assurance of anonymity. The researchers reminded participants that they could refuse to answer any question or end the interview if the participants felt uncomfortable with any question or topic; one participant asked that the researchers keep one response off the record.

Five geographically distant interviews were conducted via Skype or Google Voice, and the other interviews were conducted in person at locations of the participants' choosing. The researchers recruited participants through opportunistic sampling: through requests from personal contacts, at an academic conference, and via participants' libraries' internal mailing lists. Interview times averaged about one hour. Seven 
interviews were conducted by one of the two researchers and two were conducted jointly. The first interview took place in October 2010 and the last in March 2011.

To gain an overall sense of each librarian's job and environment, the researchers first asked participants to describe their responsibilities and their use of information and communication technologies (ICT). All participants said they primarily use email for mediated communication with patrons, colleagues, and others, such as vendors. A large portion of emails are received though internal and external mailing lists. Many of the participants' libraries have Twitter and Facebook accounts but most were not personally involved with those services. Participants use (or have tried) a variety of online tools (i.e., wikis, blogs, Google Docs, Sharepoint) to manage or coordinate communication and project documentation. Most use (or have used) chat software to communicate with their users. All participants indicated that they hold a high degree of competence with many technologies. Job responsibilities were varied and include reference (broadly defined), instruction, collection development, committee work for university and professional associations, web development, consultation, some cataloging, conference participation, including presenting and managing, and some research and publishing.

The interviews followed a semi-structured protocol designed to foster discussion about the meaning of reference work within the context of various communication technologies (Appendix A). The protocol was designed to gather information about two broad questions regarding the participants' experience with communication overload and the "contexts or situations" that led to the experience (Creswell, 2007, p. 61). The initial questions were designed to have them describe their work and to establish rapport. Additional questions asked them to describe how ICTs were used in their work environment and their feelings about the methods used for communication with users and colleagues. More experienced participants were able to describe the evolutionary aspect of the integration of ICTs into librarianship.

\section{Participants}

Six of the participants were female and three were male. All participants hold a master's degree in library and information science. Four have an additional master's degree in English, Education, Information Systems, or History. The participants often work with users in the advanced stages of academia, such as graduate students, medical students, and faculty. On-the-job experience varied from one to twenty-five years. Four had less than five years experience. The focus of this project is on reference librarians, but two of the participants were administrators and supervisors of reference 
and instruction librarians---both with extensive reference experience.

\section{Analysis}

The interviews were recorded, transcribed as plain text documents, then imported into RQDA (Huang, 2010), a qualitative analysis package for The R Project for Statistical Computing application (R Development Core Team, 2011), which is free and open source software (GNU Operating System, 2011). RQDA facilitates coding, category building, and project management. We used this software to code and annotate the transcripts as well as maintain project logs, notes, and memos.

Transcript analysis followed Creswell's (2007, p. 159) suggestions. Following transcription, we read and re-read the interviews, identified significant statements related to communication overload, a process referred to as horizontalization (p. 61), assigned codes to these statements, and then formed "clusters of meaning from these significant statements into themes" (p. 61). Next we derived composite structural and textual descriptions, which detail how the participants experienced the phenomenon and what the participants experienced. Finally, we describe the essence of the communication overload experience shared by all the participants.

We coordinated data analysis through (Creswell, 2009, p. 190) conversing, identifying overlaps in the data, and checking that codes did not drift from one transcript to another. This allowed us to negotiate a set of 123 significant statements directly relevant to communication overload and to its intersection with the individuals' work environment and their affective states. These statements dealt with the participants' experience with the following: using email, focusing on work, handling interruptions, meeting challenges, dealing with communication based frustrations, and forming strategies to manage communication and work.

Phenomenological research requires bias clarification. The inspiration for this study arouse out of our own experiences with communication overload, from interruptions hindering work and interfering with a sense of well-being; this experience was confirmed in readings from both scholarly and popular literature. We anticipated finding that participants would describe similar problems since they use many communication technologies and receive many messages as a part of their professional lives. To correct for this anticipation, we made every attempt to bracket our experiences (as described by Creswell, 2007, p. 59) by asking neutral questions and rephrasing 
questions when participants seemed to provide correct answers. As Anderson and Spencer (2002) write, the process "is an attempt to approach a lived experience with a sense of 'newness' to elicit rich and descriptive data" (p. 1341).

The holistic, complicated, and sophisticated world the participants painted resulted in comments and statements that contradict several of the themes. This negative or discrepant information works as a validation strategy. These contradictory statements are outlined throughout the findings. The final strategy we used for validation was peer debriefing. We asked another researcher (see article by-line for attribution) with expertise on this subject to help insure that our "account will resonate with people other than the researcher" (p. 192). We sent her a near final draft of this paper and she provided extensive comments and suggestions, which the authors read, discussed, and used to increase the paper's clarity.

\section{Findings}

The basis of this research, as noted, is the experience of the researchers. Theoretical discussions in the literature verified our findings. The coding process involved finding significant statements in the interview transcripts and reducing these statements into themes. Seven themes emerged from this process: Attending to Communication Abundance, Librarians of Two Types, Instruction Not Reference, Twenty-first Century Librarianship, User Needs, Trusted Methods: Filter Not Retrieve, and Self Impact. Structural and textual descriptions were formulated from these seven themes, which led to an articulation of the essence of communication overload for the participants. This essence, the shared meaning among these librarians, is that communication overload is a problem when it detracts from or hinders their ability to assist their users.

\section{Attending to Communication Abundance}

The participants described a need to keep pace with the abundant flow of communication. It is common for participants to receive up to or over 1,000 emails per week. As Participant (3) noted, "I don't know... a lot. More than I can read. I've got more than 4,000 emails in my inbox." Although seemingly excessive, we might wonder if it is

enough for overload. To draw such a conclusion, several factors are at play beyond the amount of emails or other communications received. In addition to how the participants feel about the amount, these other factors include the amount of attention these 
communications require by the participants, how many different sources of communication must be attended to, and who is sending these communications. With regards to the amount received and the attention needed, Participant (2) was able to frame the scenario by describing his inbox upon return from vacation:

I can easily, if I go away for a week, I can easily have 1,200 messages waiting for me. But most of them can be dismissed out of hand, and that's not counting spam [....] It does take a lot of time. And part of it is time management on the part of the librarian. When I get back from a week long vacation it can easily take me an hour and a half to sort through all my email even though most of it I'm deleting (Participant 2).

Most of the participants noted that only a small portion of these communications originate from users. Participant (7) said, "right now it's pretty busy, so maybe everyday I'm getting something [from users], but other times, slower times, it's less." However, email originating from colleagues and mailing lists, which all participants value as important yet excessive sources of communication, dominated most email communications. Since most of these emails are not always pertinent, the participants describe spending considerable time cleaning out their in-boxes: "Most of them are garbage, just delete, delete, delete [...] you know, need to know about it but delete" (Participant 5). Despite the time spent filtering and deleting, continual subscription to the mailing lists seems too valuable to give them up. In some cases, as with internal, university or departmental mailing lists, subscriptions are mandatory.

The multitude of emails drives some to explore other tools they believe will help make communication more efficient, but the sheer volume of email prevents them from considering other options. Participant (1) wanted her colleagues to use internal wikis and blogs to manage communication, but she faced resistance. She said:

But to me there's the problem that everything goes back and forth via email and sometimes it's hard to find the needle in the haystack when you receive hundreds of emails everyday. But I think I saw in my fellow librarians they balked at having another tool they would have to check (Participant 1).

Participant (1)'s desire to communicate more efficiently resulted from email overload--too much email that requires too much attention, constantly coming in throughout the day. For her, this overload hinders her ability to focus and delve deeply into a project or 
thoroughly explore a promising idea. Others expressed similar concerns. The constant interruptions limit and hinder opportunities to engage deeply with a topic or an issue.

Participant (4) noted:

I can just get inundated with email, I need to teach myself to not check my email five times an hour. I did take the little alert off so it doesn't pop every time I get an email in the corner of my, um, but that seems to be the biggest problem, is email, I just get tons of email, just little tasks that have to be done and responded to, take up a good portion of the day. (Participant 4).

Others mentioned losing the ability to focus. Participant (5) spoke about problems with multitasking and expressed doubt that it was possible to do so. She said,

depending on what your two tasks are, your brain actually can't process, you're actually not processing both at the same time, you're actually stopping one thing and picking up another, and that if you just had focused on this thing, you would be done with your day an hour and a half earlier (Participant 5).

Despite this, Participant (5) also spoke of the irony of interruptions---that while it is frustrating and difficult to manage, they are also a source of work and a means to engage users: "our work comes from the interruptions, like the way I get my work is through email. And so it's really hard to know what you can tune out and not tune out" (Participant 5).

\section{Librarians of Two Types}

Throughout the interviews, we continually asked respondents to reflect on how they communicate, and we discussed both mediated (i.e., digital) communication and face-to-face communication. We found two different general attitudes about their receptivity towards different communication tools---some noting their usefulness while others noting the opposite. Some enthusiastically embrace a wide variety of communication technologies in both their personal and professional lives, seeing themselves as emerging technology leaders. Others find their work duties upended by these tools. A few resign themselves to learning what they need for their job, and one had abandoned cell phones and social networking in her personal life. One participant, who spends time between two libraries on the same campus, sought recourse to more 
technology and summed up her ability to manage these duties in four words: "I got an iPad" (Participant 3).

While all participants felt frustration with technology (sometimes with specific technologies), those who embraced them seemed inclined to feel more frustration with the wrong use of a technology, such as email, while those less engaged or enthusiastic about the next great thing expressed either general frustration or uncertainty. Participant (1), a technology enthusiast who wished that her colleagues would adopt more efficient tools, might assign herself to this wrong use camp:

I won't tell you there aren't times when I don't get overwhelmed, but it's not the variety of tools because my job and my interest is all about playing with them, but I do have a lot of frustration with email in particular (Participant 1).

Others want to explore and adopt new technologies but seem to face cognitive or affective barriers due to the amount of work involved. Compare Participant (1)'s frustration above with Participants (6) and (4)'s frustration:

That whole learning fatigue, just because there is so much. I do find that there is...I'm very, very selective when I decide what I'm going to come anywhere close to mastering, because it's not worth it. (Participant 6).

I even went to one of those classes on 'managing your inbox in Outlook' and all of these different tools and colors and priorities and all the task lists, and I just don't use any of it. (Participant 4).

In sum, most of the participants felt that they were proficient users of technology, but the problems lie in selecting which tools would most easily address the different communication needs they faced. This resulted in disjointed communications between colleagues, caused by the both the array of tools available for management of information and communication, and disagreement about which tools would be best for sharing projects.

\section{Instruction Not Reference}


The importance of instruction and information literacy to the librarians' jobs and to their users is strongly supported in this study. This importance also emphasizes the participants' concern about their users and illustrates the environment that drives much communication. Specifically, the participants often collaborate with other departments or classes in order to ensure that students learn, for instance, how to effectively search databases. Julien and Genuis (2011), in researching librarians' teaching roles, found (among other things) that teacher-librarians felt that their teaching role enhances "institutional goals" (p. 930).

Vaagan and Holm (2004) identify as the most important values among academic librarians being "free access to materials and to information" and "spreading information literacy" (p. 216). These two values emerge in the forms of reference and instructional work. The participants in this study seem to confirm these dual and complementary responsibilities with perhaps more of an emphasis on instruction. That is, they implicitly described themselves in ways that identified them as instructors rather than as reference librarians. Participants (8) and (2) summed it most succinctly: "the purpose of the job is mainly instructional, there are also collection development responsibilities, and of course reference hours" (Participant 8); and "Reference and instruction are probably the two most visible things. Instruction probably more, surprisingly more than reference" (Participant 2). With regards to communication overload, this self-perception highlights a complex and active relationship with users:

Well, we've got a very, very active instruction program--information literacy program, we're running something like 250 to 300 classes a semester through that program. (Participant 7).

Rather than finding the answer to simple and straightforward questions, the participants spend more time teaching strategies and helping users become independent. Participant (2) described his instructional classes:

Most of it's database instruction. Sometimes other types of tools, if you regard statistical abstracts of the U.S. as a tool or database, things like that. We also talk to them a little bit about strategy, at least I do, using the databases, using search results for the content but also to identify alternative search terms, the advantages of certain databases over others [...] (Participant 2). 
The participants felt that more intense and involved interaction with their users has become the norm. In one sense, they view the reference desk as an inadequate place for these reference transactions (one library where two of the participants work retired the desks) since assistance often requires a substantial commitment best accomplished repeatedly or asynchronously. Participant (4) commented on this and on the desire to encourage repeat user visits:

Generally I feel that the patrons leave satisfied, that they've found an answer to their question, or at least some starting points, especially when someone is doing a big research project, you know, we can't do it all in 20 minutes at the reference desk. Again, I try and give them some tools to get started, and then have them come back. (Participant 4).

However, the reference desk remains an important symbol and meeting place. Participant (1), the participant with the most enthusiasm for technology, actively uses Second Life to conduct information literacy sessions. She says that reference interviews via chat are growing in popularity, but noted the importance of the physical desk when she said, "That reference desk is the only place where it's the librarian assisting the customer right at their point of need, and I just think that's something that shouldn't be devalued" (Participant 1).

\section{Twenty-first Century Librarianship}

The twenty-first century has brought a slew of new tools for communication to the reference desk. This change was widely acknowledged by the participants in this study. While the interview question did lead the participants to explore this idea, they were able to distinguish a demarcation between 'traditional' librarianship and current practices. Participant (1) described modern librarianship as something that required an additional layer of skill sets. Not only must reference librarians be capable of finding information, they must be adept at mediated communication. While the participants expressed conflicting notions about the reference desk and its importance, the idea that reference librarians are no longer bound to it, as a focal point, pervades. In our discussion of what it means to be a reference librarian today, she said:

Well, certainly it no longer means being at a desk and necessarily having face to face interaction with the user and in fact as I said the numbers show the majority 
of our transactions are not face to face and that means a whole new set of skill sets and in many ways it's more challenging than before (Participant 1 ).

Others concurred. A recurrent response to our question about the meaning of modern librarianship was the notion that it required keeping abreast of technologies and their uses, including social networking and media sites, even if they do not use such things personally. Participant (4) expressed this clearly:

Part of it for the 21st century is to keep up with the new social media tools out there, like Twitter, IM, and Facebook and that doesn't mean I have to be involved in all them, I don't tweet, I don't twitter, ... but I know it's out there and I know how it's used, just to keep up with the technology doesn't mean you have to adopt everything, just to know it's out there (Participant 4).

Although the social aspect of these tools were often emphasized, they are essentially communication tools and therefore may contribute via their use, tracking, and so forth, to communication overload. Participant (9) phrased this eloquently when she said:

I still have this kind of perpetual fear of kind of the realization that I can't just kind of coast in what I'm doing, I'm going to continually be more aware of the ways that people are communicating and having the library be a relevant place, and to know that there will still be a need for what I do within that knowledge, to know that I can help people make sense of what all is there, and find what is valid and what is legitimate compared to just the chaff that is spread far and wide, just information (Participant 9).

Participant (9)'s reflection illustrated the connection between communication and information overload. That is, communication overload sometimes entails information overload, and it is the latter problem that seems to have a great influence on the participants' experience with modern librarianship. The participants expressed concern about what they do not know, what they know enough about but cannot anticipate, and what they have to track.

\section{User Needs}


Perhaps because the information landscape is varied, complex, and difficult, most of the participants felt highly motivated to reach out to users---in terms of outreach services, consultation sessions, and pro-active information gathering, even to the point of doing citation analyses for assistant professors' tenure reports. Involved with this is a sense that the library is redefining itself. Participant (5) conveyed this notion of the library when she said:

Well, the physical space is used much differently than it used to be used. It is actually a space for people to come and study or collaborate. They're not coming here to find information. They're coming in here to actually digest the information, to process it (Participant 5).

Participant (4) related part of her concern about these complexities. She remarked on the essential difficulty in using communication technologies to help users navigate the digital landscape. She said, "With so much online, just trying to make people aware, [you have to] show them how to get to it" (Participant 4). Participant (2) felt these technologies were often inadequate. Even though he had confidence in asynchronous communication, such as email, which enable longer and more detailed conversations with patrons, he still spoke of barriers with mediated communication: "I figure with any interaction like that, they're communicating to me through whatever filter they have, and I am reading it with whatever filter I have, and our filters might not match up" (Participant 2). Participant (7) noted that assisting users online heightened the meaning of face to face interaction: "So face to face, when it does happen, is actually that much more important because it's more complex, more difficult, they need that much more help" (Participant 7).

Participants worried about their users' information competency and also their overall well-being. When the librarian is removed from the information-seeking process, they fear that users turn to first available sources without considering quality. To prevent this satisficing, they desire to play a prominent role in this process. Their interventions take place in many venues---for instance, by visiting classes and demonstrating databases, working as 'embedded librarians', and teaching information literacy courses. Despite their efforts, the participants sometimes felt overwhelmed by the need to learn and keep abreast of the changes in tools and sources. After all, if it is a full time job to stay abreast of these changes; therefore, it must be overwhelming for their users, who have other full time jobs as students or faculty and should not necessarily be expected to do that kind of work. That worries them. Participant (6) said: 
...until those systems such as Wimba become easy enough so that someone in a panic can use them, because they are, they're panicked, they're like 'oh my god, I have to find 10 more articles, my paper's due, my kid's sick, I've got to go to work...I can't find this on here, and even Google Scholar, you know, they'll say, I've even tried Google Scholar and I couldn't find them there..." and I've been there, you know? It's not like I want to learn how to use another database or something when I need the information. It's not like they want to learn Scopus or CINAHL [Cumulative Index to Nursing and Allied Health Literature] or whatever, they just want the articles that they can read so that they can write the paper. So to give them one more thing to learn that they don't really want to learn? (Participant 6).

Due to a desire to alleviate as much stress for the user, and despite identifying themselves as hybrid instruction / reference librarians, sometimes the participants felt they have to make it easy for their users. Participant (7) summed this experience:

Potentially, I sacrifice a bit of teaching---a teachable moment, you know, showing somebody how to do something, but at the same time, in terms of managing my time and getting them what they need more quickly, working asynchronously is actually more efficient in many cases (Participant 7).

Trusted Methods: Filter Not Retrieve

Librarianship is a practice that involves a mastery of tools and skills. These skills often focus on retrieval methods. As with email abundance, though, they felt that the ability to filter trumped an ability to retrieve in an ever-expanding world of scholarly publications. This information explosion leaves the participants with a feeling that they know less and less about the information landscape, what is out there, and what is not out there. Participant (4) described filtering:

There's so much online, and now you don't know what's out there, and often times someone will come to you with a question that's like---I don't know, let's go see. And l'll search the databases and I'll search online, and it may still be out there but I don't know about it. It's hard to keep track of all the advances in all the databases and stuff (Participant 4). 
Participant (2), one of the most experienced and successful of the group, related a story about a reference exchange, when a graduate student asked for data on a very difficult topic:

And we ... I could not find resources for him. And fortunately he was in the early stages of planning his thesis so he changed his topic to something that there was data on, but there's a lot of grief and frustration with not being able to find information. If I can definitely say, there is no information here, I don't feel so bad about that. But I don't know for sure that no one collects data on [topic omitted], I just don't know that anybody does, and I was not able to find that kind of data (Participant 2).

The problem, for Participant (2), was not a lack of knowing how to search, but that he was simply unable to do the necessary work. Data and scholarly communication exist in such abundance that they described an inability to confirm the existence or the non-existence of scholarly work and data. The data abundance forces the participants to test alternative methods, such as filtering, for gathering and organizing information. Participant (5) described this situation:

it was like it took a long time to actually find something. And now it's like you find way too much. And so now it's turned to how you filter, so what is the best stuff because you can quickly, you have thousands of things to look at. It used to be that it took you a long time to find ten good articles, and now it's like its just totally exploded, and so now it's like our job has changed to do the filtering and to do the quality control of the information (Participant 5).

The participants generally felt confident that they were good at filtering and ensuring quality, but that there are still are other methods to master, but this wasn't necessarily a negative experience. Participant (2) spoke of the satisfaction of the challenge and of the process of professional self-renewal, of self-reinvention. Participant (7), another long-term librarian, described the satisfaction in this way:

That tacit knowledge of your profession is second nature to you, and it's actually sort of nice, if you're driving home in the evening and you think, you know, I was hardly conscious of what I did but what I did was high level professional work right there. You drew on all sorts of knowledge and skill sets and tool kits and 
everything else and you brought it all together...Yeah, that was pretty cool (Participant 7).

The above quotes focus on tools needed for the research process. Participants spoke of a second kind of filtering, though--one needed to prioritize work. Emails present a constant barrage of possible directions; maintaining focus was a task in itself. Participant (3) emphasized it was important to simply 'let things go'. Earlier in the interview, she outlined methods for keeping up with her busy schedule, split between two libraries. She discussed the importance of following through with commitments and her excitement about her projects. She explained that she gets hundreds of emails daily, and that it is not possible to read them all. Too much communication requires the willingness to let go of things that might take away from one's real job in order to devote time and effort to what matters.

I use this unscientific theory called sediment--stuff that falls to the bottom, if it didn't get done, well, it must mean that it didn't really mean that much to anybody. (Participant 3).

She continues:

Oh, I have a pretty good power of ignoring it [new emails]. I mean, I just sit there and ignore it for a while because if I responded every time it dinged then I wouldn't get anything done. (Participant 3).

Not all employ such discernment (letting sediment fall to the bottom). Participant (5) reported that she is often unable to distinguish the important issues that come from email from the unimportant issues, because they all might bring her work, similar to questions at the reference desk---one person arrives with a reference question, another with a question about the location of the restroom. Those are both interruptions and both require an answer. There is no easy way to filter the reference questions from the others without being interrupted. Experience might play a role in this: "our work comes from the interruptions, like the way I get my work is through an email. And so it's really hard to know what you can tune out and not tune out" (Participant 5).

\section{Self Impact}


Every participant in this study mentioned positive aspects of their work; they felt that their career as a librarian was personally fulfilling. This theme pertains to the participants' self-identification as professionals and what that means to them. In one sense, it plays out in the form of prioritization---how they separate and order their work and their personal lives. In another sense, there is also the idea that their work is personally meaningful. Communication and communication tools are key to both of these sub-themes.

Consider first prioritization. The interviews revealed two approaches to prioritization: those who strive to maintain a life/work balance by leaving work at work (thus 'unplugging' at home) and those who see home as the place to complete big projects, away from the distractions inherent in a plugged-in work environment. Participant (2) illustrates the latter by emphasizing that it is a choice to take work home. We can infer from this that communication tools have made the extended workday possible and likely:

I've learned to leave work at work. Having said that I now take more work home than I did five years ago, but it's by choice. It's by choice. (Participant 2).

Participants expressed a need to balance the two approaches and to assign work to one sphere, and family, friends, and hobbies to another. Participant (2) later continues with an explanation of this division:

I'm involved in outside things. I'm involved with my church and my family, with my neighbors, my extended family, and I think all of those things help me keep things in a balance, somebody else may do different things to keep things in a balance, but for me, it's all those things that I like doing but more importantly I need to do so that when I come to work I can work, and when I'm done I can leave and come home and sleep at night. (Participant 2).

Second, consider what takes place at work. Balance is an essential aspect of this theme, of modern librarianship's impact on the self. We did not specifically ask about this, yet the participants continually described librarianship using metaphors that point to deep feelings about their roles (e.g., it a calling, it "is part of their chromosomal makeup" (Participant 7)), or they simply described it as something they love to do. They said their 
job presented challenges and opportunities for growth, and that they felt like they were doing important work within their organizations. Their job fulfils a need in their life to look for things---the thrill of the search, and to help people:

To me, I have such a love for being able to help people find what they need, help make someone's educational journey a little bit easier, because even if I know that maybe it's not the most earth-shattering process, it's still so much impacting for someone who really needs that in a timely manner, so I get so much satisfaction out of what I do. (Participant 9).

The following quote reflects this theme of growth, but is couched within the context of some dissatisfaction with communication itself:

There are things I am less satisfied with than I was 20 years ago and that's the amount of user interaction, face to face interaction, but there are things that I am more satisfied about like confidence in my competence as a librarian, my ability to find information continues to grow. (Participant 2).

Participant (3) reflected on the other librarians who she worked with as a "high performing group of people." She described their work as intentional and deliberate: "We don't just respond, and I think that makes a difference in being able to say that we've achieved something." Planning and acting are important, but as Participant (7) said:

What I've discovered, and this may be part---l don't know how general this is--people pay attention to things when it matters for them to pay attention. So you know we talk a lot about how extremely important it is to get your message out, communicate well, etc., that's fine. You can do the best job in the world, but to communicate, you can try multiple vectors, you---the technical expertise may be as good as best practices would allow it to be, but if the person on the other end isn't paying attention or it doesn't matter to them right now, it may not do any good (Participant 7). 
In other words, librarians might try all of the communication tools that are available, but their ability to help people is limited by the willingness of the recipient to be an active participant in the learning process. Reaching out and experimenting with communication tools is a challenge that might be more frustrating than fulfilling if the efforts are not rewarded with a sense of accomplishment.

\section{Discussion}

The purpose of this research was to gain insight into librarians' experience with communication technologies and to discover if they were experiencing communication overload. Seven themes and an overall shared experience emerged from the study. One important theme, attending to communication abundance, has been similarly reported by other researchers (Dawley and Anthony, 2003). Like the participants in this study, Dawley and Anthony find that their participants saw email both as a major contributor to information overload but also as an important tool that aids productivity. They conclude their article with suggestions on email training that would help reduce unnecessary email communication.

We found the overall essence shared by the participants of this study to be grounded in concern for library users and the quality of service delivered to them. This finding is not new to librarianship; it echoes the findings of Dole et. al. (2000). In light of this study, further research might benefit from the understanding that communication is a problem when it interferes with serving the librarians' users. Furthermore, since a vast amount of the communication comes from professional peers, such research should incorporate interpersonal communication within the librarians' organizational structures as well as in their broader professional networks. Although interpersonal communication among peers is not the focus of their studies, this research does reinforce the important work produced by Dervin (1977) and Radford (1996; 2001).

\section{Composite structural description: Factors that contribute to the experience of communication overload}

The experience of communication overload in librarianship is complicated. The findings reflected in the interview statements offer a picture of a landscape and of an experience much more varied and intricate than imagined before the study---one that centers around the users they serve. Essentially, being these reference librarians involves not only achieving a level of technological proficiency but also a level of affective proficiency as they traverse a confusing and unstable landscape in their constant efforts to assist and provide patrons with the resources and the skills needed to 
succeed. These reference librarians must attend to an abundance of communication delivered, managed, stored, and retrieved using what are felt to be often inefficient and sometimes broken methods.

Different attitudes about the benefits and demands of technology, communication and otherwise, abound---attitudes that both unite and divide librarians in their selfperceptions. Digital technologies provide more access but also act as barriers between reference librarians and their users. While students continue to visit the library, as Participant (2) noted, "they come to the building for other reasons now, they don't approach librarians as often with requests for help," which is most likely the result of those same technologies: "People assume that they know how to use the Web, and they don't look to us" (Participant 2) as quickly as they used to. At the heart of the matter, of the experience with communication, lies uncertainty about how to communicate effectively the purpose of the library's existence:

Well, the physical space is used much differently than it used to be used. It is actually a space for people to come and study or collaborate. They're not coming here to find information. They're coming here to actually digest the information, to process it [... and] People sheepishly say, 'I never come to the library.' And I'm like, the library comes to you. It's right there, and they're like, 'oh yeah.' (Participant 5).

Composite textual description: The meaning of communication overload.

The participants' experiences are defined and constrained by their environment--one filled with multiple devices for establishing connections to their communities. For Participant (1), this environment is new and exciting and she faces it with an exuberant enthusiasm for the promise of its potential. For Participant (2), this environment is approached with a cautious temperament grown out of his experience with previous trends and fluctuations in communication technologies and a seeming desire to maximize his energies by remaining selective.

Despite these differences, the fundamental meaning shared by these librarians is established in a concern and a hope in the various elements associated with communication technologies: distraction, separation, perseverance, caution. Although the participants vary in age and years of experience, they all retain their individuality and integrity in this interpretation, but one senses the existence of a continuum and imagines 
that, perhaps, the newer librarians will feel as the more experienced ones after they have negotiated their way through the next few decades of change. Perhaps not though. Whatever the eventual outcome, the shared meaning among the participants seems to be a shared interest and an overriding concern for maintaining a level of excellence in their service to the user.

\section{Essence of Communication Overload: Service to the user}

Phenomenology seeks to define an essence of a thing by examining multiple presentations of subjective experiences. The subject of this research was a 'thing' called communication overload, as experienced by reference librarians in an academic setting. The shared essence that emerged, though, involved the participants' relationship with users. Communication technologies played a key role in defining this relationship, even when the communication occurs only among peers, and their feelings about these technologies was one key factor in how this relationship is formed and maintained. The concepts defined in the literature in regards to communication overload were reinforced: it is the multiple venues for communicating with users, with colleagues, and various communities that cause distraction and distress for some participants but also, often concurrently, build bridges and redefine what it means to do reference. Some deal with problems by removing or ignoring the offending technologies. Others, though, actively incorporate new technologies, exploring possibilities for using them in their work flow. Overall, the main idea presented by the librarians regarding communication was service to their patrons around which other things revolve: attention demanded by abundance, receptivity to technology, instruction, librarianship, needs, filtering, and life balance. Dole, Hurych, and Koehler (2000) cite a number of sources that identify the importance of the user as a central value and find in their own study that "nearly all librarians everywhere identify user service as their first order principle" (Conclusions section, para. 4).

The participants articulated many of their statements contextually---bounded by their relationships with their users. They identified the user as the reason for their professional existence and felt that while the current communication and technology environment does much to increase access to informational sources, it also does much to separate them from their users. As Participant (1) noted, "the students come first." Participant (2) said, "I like helping people. I really, really like helping people." Participant (7), "it's like being a social worker or a school teacher. There are a lot of what we call service professions, but there maybe needs to be an element---something that inspires you, that you have a desire to do it."

\section{Conclusion}

The interviews and the phenomenological research design proved to be a 
revealing process of inquiry into this study. We found that overload occurs not merely because of excess. Excess simply refers to too much, but what is felt to be too much is a subjective measurement. Thus, an overload event seems to occur not only when there is excess, but when that excess frustrates a person's primary purpose or their end. In the context of this study, the primary purpose for these participants is to help their users. When communication is both excessive and frustrates that end purpose, the overload event seems much more likely to be felt. This calls for more research on those professions that function as mediators of information through communication technologies. As we noted, studies often focus on the various kinds of overload and interruptions experienced by users, but given the nature of work conducted by the information professional, studies on how the professionals experience these kinds of phenomena, in the entire context of their professional life, have become necessary. While the phenomenological research design based on interviews helped provide a much greater understanding of the meaning of communication overload, other qualitative research approaches and various types of data collection would also benefit this area of research. 


\section{Appendix A: Interview Protocol}

- Will you please describe the most visible aspect of your work? Less visible?

- Tell me about the different ways patrons visit you or your library.

- Tell me about the different ways you, or your library, actively seek out patrons.

- What does it mean for you to be a librarian?

- What do you like about this work? What are the difficulties?

- What does it mean for you to be a librarian in the 21 st century?

- Do you feel there is a qualitative difference between librarianship when you began this career and librarianship today because of the technology or because of something else?

- Is there a quantitative difference, such as more communication channels, more diversity, more students, or more or less of something else? If so, what does this mean to you? What do you think are the implications?

- What does it mean to do reference work through various channels of communication?

-What and how many kind of communication technologies do you use?

- How does it feel to manage service to patrons in the ways you described?

- How do you manage, work, collaborate with other librarians either at your library or from other locations? Do you feel you and others communicate with each other efficiently?

- What does this mean to you, as far as personal implications, professional implications, long-term implications?

- How do you feel about having your work mediated through various communication technologies?

- Does this promote feelings of stress or excitement? Do you feel these technologies help you assist users or erect barriers between you and patrons? Have these various forms of communication affected job satisfaction? Have you ever associated communication maintenance and monitoring with your health or well-being? 



\section{References}

Anderson, E.H. and Spencer, M.H. (2002), "Cognitive representations of AIDS: a phenomenological study", Qualitative Health Research, Vol. 12 No. 10, pp. 1338-52.

Bawden, D. and Robinson, L. (2008), "The dark side of information: overload, anxiety and other paradoxes and pathologies", Journal of Information Science, Vol. 35 No. 2, pp. 180-91.

Bernet, R., Kern, I., and Marback, E. (1993), An introduction to Husserlian Phenomenology. Northwestern University Press, Evanston, IL.

Budd, J. (2005), "Phenomenology and information studies", Journal of Documentation, Vol. 61 No. 1, pp. 44-59.

Carr, N. (2008), "Is Google making us stupid? What the Internet is doing to our brains", The Atlantic, July/August, available at:

http://www.theatlantic.com/magazine/archive/2008/07/is-google-making-us-stupid/6868/ (accessed 1 September 2010).

Case, D.O. (2007), Looking for Information: A Survey of Research on Information Seeking, Needs, and Behavior, Second Edition, Elselvier/Academic Press, Amsterdam.

Chamberlin, J.G. (1974), "Phenomenological methodology and understanding education", in Denton, D. (Ed.), Existentialism and Phenomenology in Education: Collected Essays, Teachers College Press, Columbia, NY, pp. 119-37.

Conklin, T. (2007), "Method or madness: phenomenology as knowledge creator," Journal of Management Inquiry, Vol. 16 No. 3, pp. 275-87.

Connelly, M. (2010), "More Americans sense a downside to an always plugged-in existence", The New York Times, 6 June, available at:

http://www.nytimes.com/2010/06/07/technology/07brainpoll.html (accessed 1 September 2010).

Creswell, J.W. (2007), Qualitative Inquiry \& Research Design: Choosing among Five Approaches, Second Edition, Sage Publications, Thousand Oaks, CA.

Creswell, J.W. (2009), Research Design: Qualitative, Quantitative, and Mixed Methods Approaches, Third Edition, Sage Publications, Los Angeles, CA. 
Dawley, D.D. and Anthony, W.P. (2003), "Users perceptions of e-mail at work", Journal of Business and Technical Communication', Vol. 17 No. 2, pp. 170-200.

Dempsey, L. (2009), "Always on: libraries in a world of permanent connectivity", First Monday, Vol. 14 Nos 1-5, available at:

http://firstmonday.org/htbin/cgiwrap/bin/ojs/index.php/fm/article/view/2291/2070. (accessed 1 September 2010).

Dervin, B. (1977), "Useful theory for librarianship: Communication, not information", Drexel Library Quarterly, Vol. 13 No. 3, pp. 16-32.

Dole, W.V., Hurych, J.M., and Koehler, W.C. (2000), "Values for librarians in the information age: an expanded examination", Library Management, Vol. 21, No. 6, pp. 285-97.

GNU Operating System (2011), "The Free Software Definition", available at: http://www.gnu.org/philosophy/free-sw.html (accessed 10 July 2011).

Huang, R. (2010), "RQDA: R-based qualitative data analysis", available at: http://rqda.rforge.r-project.org/ (accessed 10 July 2011).

Janes, J. (2002), "Digital reference: reference librarians' experiences and attitudes", Journal of the American Society for Information Science and Technology, Vol. 53 No. 7 , pp. 549-66.

Julien, H. and Genuis, S.K. (2011), "Librarians' experiences of the teaching role: a national survey of librarians", Library \& Information Science Research, Vol. 33 No. 2, pp. 103-11.

Karr-Wisniewski, P. and Lu, Y. (2010), "When more is too much: operationalizing technology overload and exploring its impact on knowledge worker productivity", Computers in Human Behavior, Vol. 26 No. 5, pp. 1061-72.

Lamb, G.M. (2010), "Are iPads, smartphones, and the mobile web rewiring the way we think?", The Christian Science Monitor, July 24, available at:

http://www.csmonitor.com/Innovation/Tech/2010/0724/Are-iPads-smartphones-and-theMobile-Web-rewiring-the-way-we-think (accessed 1 November 2010).

Mark G., Gudith D., Klocke U. (2008), "The cost of interrupted work: more speed and stress", in Proceeding of the Twenty-Sixth Annual SIGCHI Conference on Human Factors in Computing Systems in Florence, Italy, CHI 2008, ACM, New York, pp. 107- 
110, available at: http://interruptions.net/iterature/Mark-CHI08.pdf (accessed 5 January 2012).

Melchionda, M.G. (2007), "Librarians in the age of the Internet: their attitudes and roles", New World Library, Vol. 108 Nos 3/4, pp.123-40.

R Development Core Team. (2011), "R: a language and environment for statistical computing", available at: http://www.r-project.org/ (accessed 27 September 2011).

Radford, M.L. (1996), "Communication theory applied to the reference encounter: an analysis of critical incidents", The Library Quarterly, Vol. 66 No. 2, pp. 123-37.

Radford, M.L. (2001), "Encountering users, encountering images: communication theory and the library context", Journal of Education for Library and Information Science, Vol. 42 No. 1, pp. 27-41.

Richtel, M. (2010a), "Digital overload: your brain on gadgets", interviewed by Gross, T., [radio], WHYY for National Public Radio, 24 August 2010, available at:

http://www.npr.org/templates/transcript/transcript.php?storyld=129384107 (accessed 27 September 2010).

Richtel, M. (2010b), "Digital devices deprive brain of needed downtime", The New York Times, 24 August, available at: http://www.nytimes.com/2010/08/25/technology/25brain.html (accessed 1 November 2010).

Savolainen, R. (1995), "Everyday life information seeking: approaching information seeking in the context of 'way of life'", Library and Information Science Research, Vol. 17 No. 3, pp. 259-94.

Savolainen, R. (2007), "Filtering and withdrawing: strategies for coping with information overload in everyday contexts", Journal of Information Science, Vol. 33 No. 5, pp. 61162.

Sibley, K. (1997), "Communications overload is hindering work: study', Computing Canada, Vol. 23 No. 11, p. 6.

Vaagan, R. and Holm, S. (2004), "Professional values in Norwegian librarianship", New Library World, Vol. 105 Nos 5/6, pp. 213-17.

Wu, M. M. (2005), "Why print and electronic resources are essential to the academic law library," available at: http://www.aallnet.org/main-menu/Publications/lij/LLJ-Archives/Vol97/pub_llj_v97n02/2005-14.pdf (accessed September 27, 2011). 